\title{
Analysis of individual items on the attention- deficit/hyperactivity disorder symptom rating scale in children and adults: the effects of age and sex in pivotal trials of lisdexamfetamine dimesylate
}

This article was published in the following Dove Press journal:

Neuropsychiatric Disease and Treatment

6 December 2013

Number of times this article has been viewed

\section{Richard H Weisler ${ }^{1,2}$ \\ Lenard A Adler ${ }^{3}$ \\ Scott $\mathrm{H}$ Kollins ${ }^{4}$ \\ David W Goodman ${ }^{5}$ \\ Mohamed Hamdani ${ }^{5}$ \\ Bryan Dirks ${ }^{6}$ \\ Ann C Childress ${ }^{7}$}

'Duke University Medical Center, Durham, NC, USA; '2University of North Carolina at Chapel Hill, Chapel Hill, NC, USA; ${ }^{3}$ New York University School of Medicine and Psychiatry Service, New York VA Harbor Healthcare System, New York, NY, USA; ${ }^{4}$ Duke University Medical Center, Durham, NC, USA ${ }^{5}$ Johns Hopkins University School of Medicine, Baltimore, MD, USA; ${ }^{6}$ Shire Development LLC, Wayne, PA, USA; ${ }^{7}$ Center for Psychiatry and Behavioral Medicine, Las Vegas, NV, USA
Correspondence: Richard H Weisler 700 Spring Forest Road, Suite 125 ,

Raleigh, NC 27609, USA

Tel + I 9198725900

$\mathrm{Fax}+\mid 9198780942$

Email rweisler@aol.com
Background: Attention-deficit/hyperactivity disorder (ADHD) symptom presentation across age and sex has not been fully elucidated. The present post hoc analyses qualitatively explored the baseline levels of ADHD symptomatology across subgroups in two clinical trials of children and adults with ADHD to elucidate differences in participant presentation. The response to treatment was examined to determine patterns of response among items of the ADHD Rating Scale IV.

Methods: Exploratory post hoc analyses of ADHD Rating Scale IV item scores were conducted on data from two 4-week placebo-controlled trials in children (6-12 years) and in adults (18-55 years) with ADHD. Baseline and endpoint mean item scores were determined for subgroups defined by age (6-9, 10-12, 18-39, and 40-55 years) and sex.

Results: The baseline mean item scores were generally numerically similar for all age-by-sex subgroups. The inattention (IA) items were numerically higher than hyperactivity/impulsivity (H/I) items among older children and adults. The endpoint mean item scores were numerically lower after lisdexamfetamine dimesylate treatment for IA and H/I items in all subgroups.

Conclusion: These results suggest that regardless of age or sex, baseline IA and H/I symptom profiles were comparable; however, IA vs H/I symptoms were more severe in older participants. In all age-by-sex subgroups, IA and H/I symptoms appeared to decrease after active treatment.

Keyword: ADHD symptom items

\section{Introduction}

Attention-deficit/hyperactivity disorder (ADHD), characterized by hyperactivity, impulsivity, and attention abnormalities, affects approximately $8 \%$ of children (aged 8 to 15 years) in the United States. ${ }^{1}$ Recent data from the US Centers for Disease Control and Prevention ${ }^{2}$ reported 5.4 million children with ADHD by 2007, a 22\% increase over statistics from 2003. While most frequently identified in childhood, ADHD persists into adulthood in $\sim 50 \%{ }^{3}$ to $75 \%$ of cases, ${ }^{4}$ impacting an estimated $4.4 \%$ of US adults (aged 18 to 44 years). ${ }^{5}$ Relatively little is known about whether and how specific ADHD symptoms and their response to treatment may be related to demographic variables, such as patient age or sex. A clear understanding of the relationship between patient variables, such as age and sex, and expression of symptoms 
might help clinicians better understand the needs of individual patients and better approach the management of ADHD symptoms.

The relationship of patient variables, such as age and sex, to the developmental course of ADHD symptom presentation has been the focus of research interest in recent years. In longitudinal studies, as participants mature, symptoms of inattention (IA) appear to persist, while symptoms of hyperactivity or impulsivity (H/I) are more likely to diminish. ${ }^{6-8}$ In line with such findings, other studies have found rates of $\mathrm{H} / \mathrm{I}$ symptoms to be age related ${ }^{9,10}$; in one investigation of adult ADHD, Diagnostic and Statistical Manual of Mental Disorders, Fourth Edition-Text Revision (DSM-IV-TR)defined symptoms reported by more than $90 \%$ of subjects were consistent with IA, or a combined subtype, while only $2 \%$ reported predominantly H/I-type symptoms. ${ }^{10,11}$ Results of a recent survey of data from the National Comorbidity Survey Replication and a large managed health care plan found a greater persistence of childhood IA vs H/I symptoms in adults with ADHD. ${ }^{12}$ However, these apparent age-related differences in symptom presentation may reflect an issue with diagnostic criteria rather than an actual change. Hyperactivity may be manifested, in adults, with feelings of restlessness or difficulty waiting. ${ }^{13,14}$ Adults with ADHD also often report or exhibit impulsivity, ${ }^{15-17}$ marked clinically by such behaviors as explosive emotional episodes, ${ }^{14}$ quitting jobs, impulsive aggression, binge drinking, dangerous vehicle driving, substance use, and dropping out of school. ${ }^{18}$ To allow for the full assessment and breadth of the adult presentation of ADHD symptoms, a set of adult prompts or descriptions of example adult behaviors has been developed. These prompts enhance the ability of patients and raters to identify adult symptoms and can be inserted into symptom rating scales, such as the ADHD Rating Scale IV (ADHD-RS-IV). ${ }^{9}$

ADHD symptom presentation also varies by sex; thus, school-aged girls with ADHD are diagnosed more often with the predominantly IA subtype than are boys with ADHD. ${ }^{19-21}$ In one investigation, the IA subtype accounted for $34 \%$ of ADHD cases in girls vs $22 \%$ of cases in boys. ${ }^{21}$ In adults, it is unclear whether this subtype pattern holds true. Although women and men appear equally likely to be diagnosed with ADHD and the majority receive a diagnosis of combined type, it is unclear whether subtype expression differs by sex and whether the higher proportion of IA subtype seen in female children holds for adult women. ${ }^{22,23}$ Again, the degree to which such findings reflect limitations of the current DSMIV-TR diagnostic criteria, sampling bias, or true symptom differences/similarities among women and men with ADHD is not known. Another limitation may be the agreement or concordance of rating between patient self-assessment of symptoms and informant assessment for both current adult symptoms and prior childhood symptoms. A study by Zucker et $\mathrm{al}^{24}$ found a moderate correlation between self- and informant ratings, with sex as a moderating factor.

Psychostimulants, including formulations containing amphetamines or methylphenidate, are a mainstay in the pharmacological treatment of ADHD for children and adults. ${ }^{25,26}$ Response to stimulant therapy is robust in both children ${ }^{27}$ and adults. ${ }^{28}$ Lisdexamfetamine dimesylate (LDX) is a long-acting prodrug stimulant indicated for the treatment of ADHD in children (aged 6 to 12 years), adolescents (aged 13 to 17 years), and adults. ${ }^{29}$ LDX is currently approved for treatment of ADHD in the United States, Canada, and Brazil. In a 4-week, randomized controlled trial in children ${ }^{30}$ and similarly, in a 4-week, randomized controlled trial in adults, with $\mathrm{ADHD},{ }^{31} \mathrm{LDX}$ was shown to be effective vs placebo in reducing ADHD symptoms, as assessed by a global improvement measure.

Analysis of individual DSM-IV-TR-defined symptoms, based on symptom scores of the corresponding ADHD-RSIV item questions, can provide useful information about symptom presentation similarities and differences across patient subgroups of different ages and sexes. The purpose of the current post hoc subgroup analysis was to describe the profile of individual DSM-IV-TR symptoms of ADHD, as assessed by ADHD-RS-IV scores on individual items, both at baseline and in the change from baseline with LDX treatment, in the children and adults with ADHD who participated in two double-blind, placebo-controlled, parallel-group, 4-week studies of the efficacy of LDX vs placebo. A number of other clinical trials of LDX in children or adults were not included, based on dissimilar study design features, such as open-label, unblinded design, crossover design, or length of study. ${ }^{32-37}$ The present analyses explored the levels of ADHD symptomatology across the subgroups in these two studies, at baseline and after treatment, to elucidate qualitative differences in participant presentation. The response to treatment was also examined to determine patterns of response among items.

\section{Methods}

\section{Study overview}

An exploratory set of post hoc analyses was based on data from two similarly designed 4-week, multicenter, placebocontrolled, double-blind, parallel-group, forced doseescalation trials in both children (aged 6 to 12 years) ${ }^{30}$ and adults (aged 18 to 55 years) ${ }^{31}$ with ADHD. Participants were 
randomly assigned in either a $1: 1: 1: 1$ ratio (pediatric study) or a 2:2:2:1 ratio (adult study) to receive once-daily, oral LDX $(30,50$, or $70 \mathrm{mg})$ or placebo for 4 weeks. Each study included a screening/washout phase and a 4-week, doubleblind treatment phase with LDX vs placebo. After screening, all eligible participants were randomized to receive LDX or placebo. The LDX treatment was initiated with the $30-\mathrm{mg} / \mathrm{d}$ dose for all participants randomized to receive LDX. For participants assigned the higher LDX doses of 50 or $70 \mathrm{mg} / \mathrm{d}$, the dose was increased in 20-mg increments at weekly intervals until the assigned dose was achieved.

The investigations were performed in accordance with the Declaration of Helsinki and the International Conference on Harmonization guidelines for Good Clinical Practice. Before initiation of any study procedures, the parents/guardians of all prospective pediatric participants and all adult participants provided informed consent, and pediatric participants gave their assent after receiving written information and an explanation of what the study involved..$^{30,31}$

\section{Participants}

The study enrollment requirements have been described in detail previously. ${ }^{30,31}$ Briefly, otherwise healthy children (aged 6 to 12 years) diagnosed with ADHD (H/I or combined subtype) or adults (aged 18 to 55 years) diagnosed with ADHD (irrespective of subtype) according to DSM-IV-TR criteria, based on psychiatric interview, were enrolled. A baseline ADHD-RS-IV score $\geq 28$ was required. Excluded were individuals with ADHD IA subtype; comorbid psychiatric disorder; history of seizures (excluding febrile seizures); tic disorder; current diagnosis or family history of Tourette disorder; specific cardiac conditions, hypertension, taking medications affecting blood pressure or heart rate (with the exception of ADHD therapy), or a family history of cardiac conditions reflecting increased potential risk for sudden death; significantly overweight or obese participants; those for whom stimulant therapy was contraindicated; pregnant or nursing females; those with a positive urine drug result at screening or baseline; and those whose current medication use might confound the results of the study or increase risk to the participant. Oppositional defiant disorder and conduct disorder were not exclusion criteria for participation in these studies.

\section{Treatment outcomes}

The primary outcome in both trials was change in the clinician-rated ADHD-RS-IV total score from baseline to endpoint; for the adult trial, the ADHD-RS-IV with adult prompts $^{9}$ was used. Treatment endpoint was defined as the last postrandomization treatment week for which a valid ADHD-RS-IV score was obtained. The ADHD-RS-IV, administered at baseline and each postrandomization visit, contains 18 items (as listed in Figures 1-3) corresponding to DSM-IV-TR ADHD diagnostic criteria. ${ }^{38}$ The items are scored between 0 (no symptoms) and 3 (severe symptoms). In addition to the ADHD-RS-IV total score (range 0 to 54), the instrument can be subdivided into two subscales: IA (odd-numbered items) and H/I (even-numbered items), each with possible scores ranging from 0 to 27 .

\section{Safety assessments}

The safety assessments included spontaneously reported adverse events (AEs), vital signs, electrocardiogram (ECG), routine clinical laboratory assessments, and physical examination (eg, height and weight). Safety findings for these trials have been previously described in detail ${ }^{30,31}$ and will not be further discussed in the current report. Treatment-emergent AEs (TEAEs) referred to events with onset after the first date of treatment and no later than 3 days following the termination of treatment.

\section{Statistical analyses}

These exploratory post hoc analyses examined individual scores for each of the 18 ADHD-RS-IV items among subgroups of participants, defined according to age and sex, in the treated population (ie, randomized participants who received double-blind treatment with at least one postrandomization primary measure). For this analysis, participants were dichotomized into male and female subgroups and were further divided according to age: 6 to 9 years, 10 to 12 years, 18 to 39 years, and 40 to 55 years. The subgroups of those aged 6 to 9 years and 10 to 12 years were chosen to differentiate childhood from the period of transition to adolescence; similarly, the adult subgroups, aged 18 to 39 years and 40 to 55 years, were chosen to differentiate young adulthood from middle age. Individual ADHD-RS-IV item scores with standard deviations (SD) at baseline and endpoint were assessed by these age-by-sex subgroups. For the purposes of these analyses, the results were collapsed across the LDX dose groups. These were exploratory post hoc analyses with small sample sizes in certain subgroups; therefore, further comparative statistical analyses were not performed.

\section{Results \\ Participants}

Participant disposition and demographic characteristics (Table 1) have been presented in detail in prior reports. ${ }^{30,31}$ 


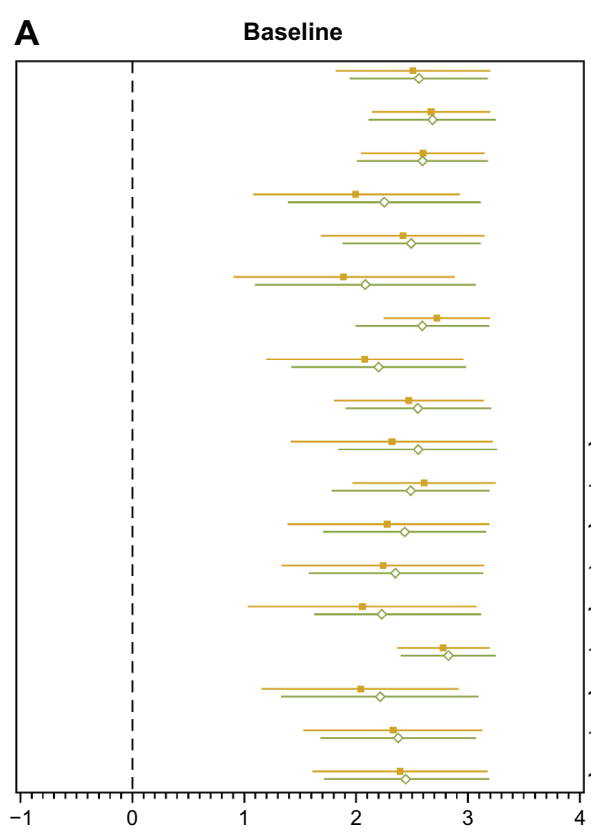

ADHD-RS-IV item score, mean \pm SD

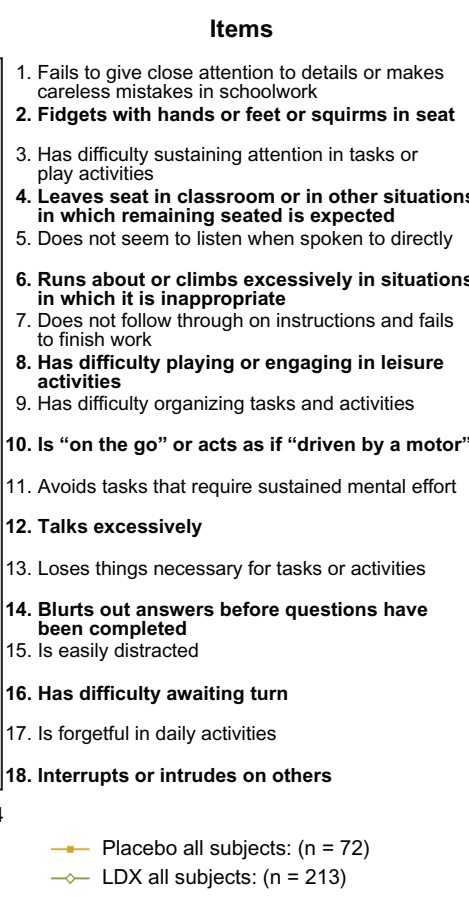

-Placebo all subjects: $(n=72)$
Items

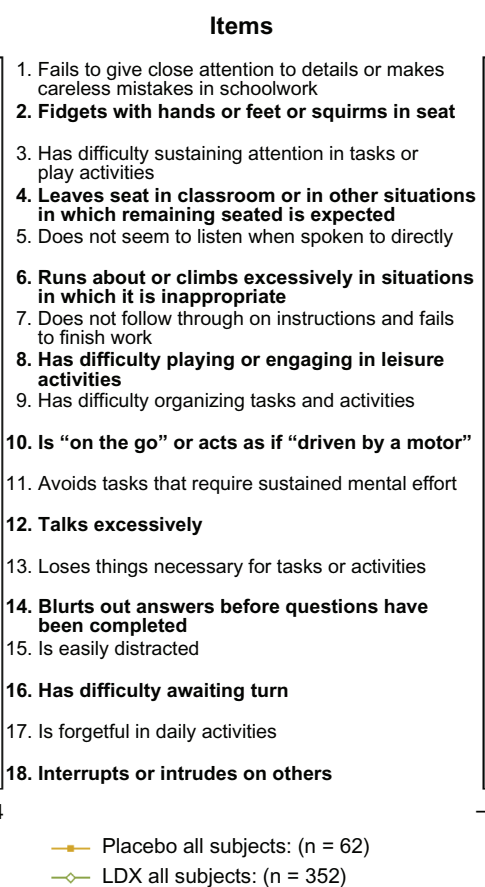

$\rightarrow-$ LDX all subjects: $(n=352)$

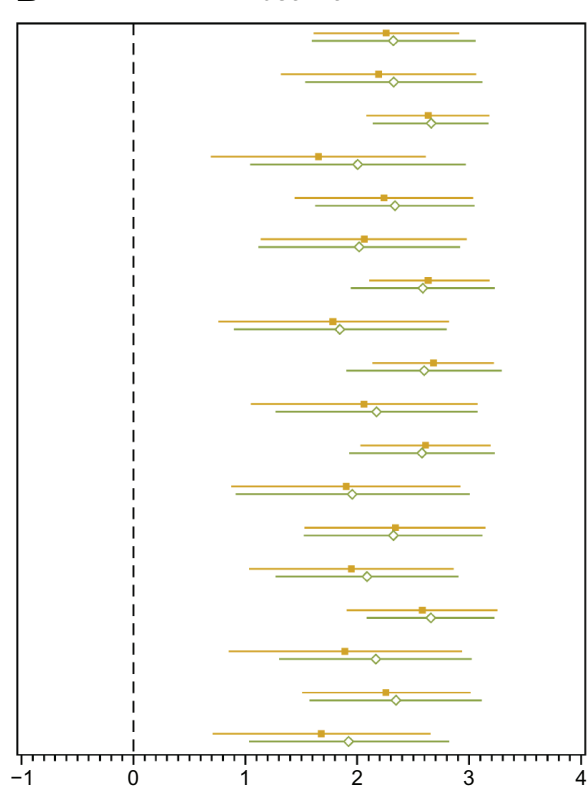

ADHD-RS-IV item score, mean \pm SD

B
Endpoint

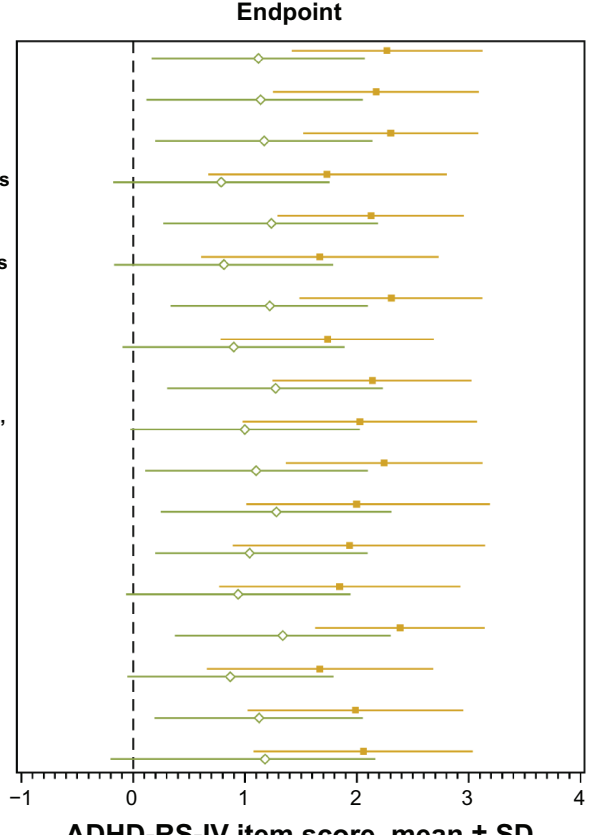

ADHD-RS-IV item score, mean \pm SD

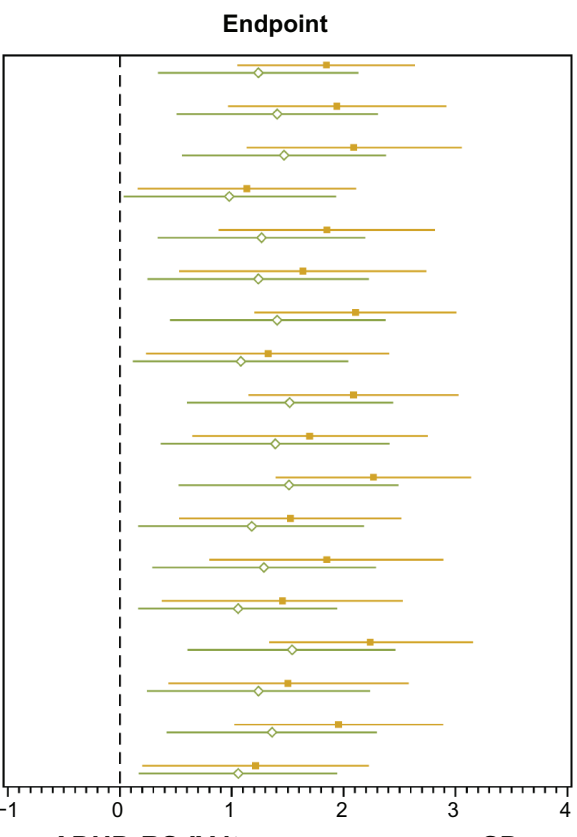

ADHD-RS-IV item score, mean \pm SD

Figure I ADHD-RS-IV mean item scores overall at baseline and endpoint, in (A) the child study and (B) the adult study.

Notes: (C) 1998 Guildford Press. Adapted with permission from DuPaul GJ, Power TJ, Anastopoulos AD, Reid R. ADHD Rating Scale-IV: Checklists, Norms, and Clinical Interpretation. New York, NY: Guilford Press; $1998 .{ }^{38}$ Odd numbers = inattention items; even numbers = hyperactivity/impulsivity items. Adult prompts were used in the adult study. Bold text represents a hyperactivity/impulsivity item.

Abbreviations: ADHD-RS-IV, Attention-Deficit/Hyperactivity Disorder Rating Scale IV; LDX, lisdexamfetamine dimesylate; SD, standard deviation.

Briefly, in the pediatric and adult trials, respectively, 290 and 420 participants enrolled and were randomized. Of these, the treated populations comprised 285 and 414 participants, respectively. Among participants who discontinued the pediatric or adult trials, TEAEs were the most frequent reason given for discontinuation $(\mathrm{LDX}=20$, placebo $=1$ in the pediatric trial;
$\mathrm{LDX}=20$, placebo $=1$ in the adult trial). Among the participants in both trials, more than half were male. In the pediatric trial, approximately half were Caucasian; in the adult trial, a large majority were Caucasian. Among the 421 males in the treated populations of both studies, 119 were aged 6 to 9 years, 78 were aged 10 to 12 years, 153 were aged 18 to 39 years, and 71 were 

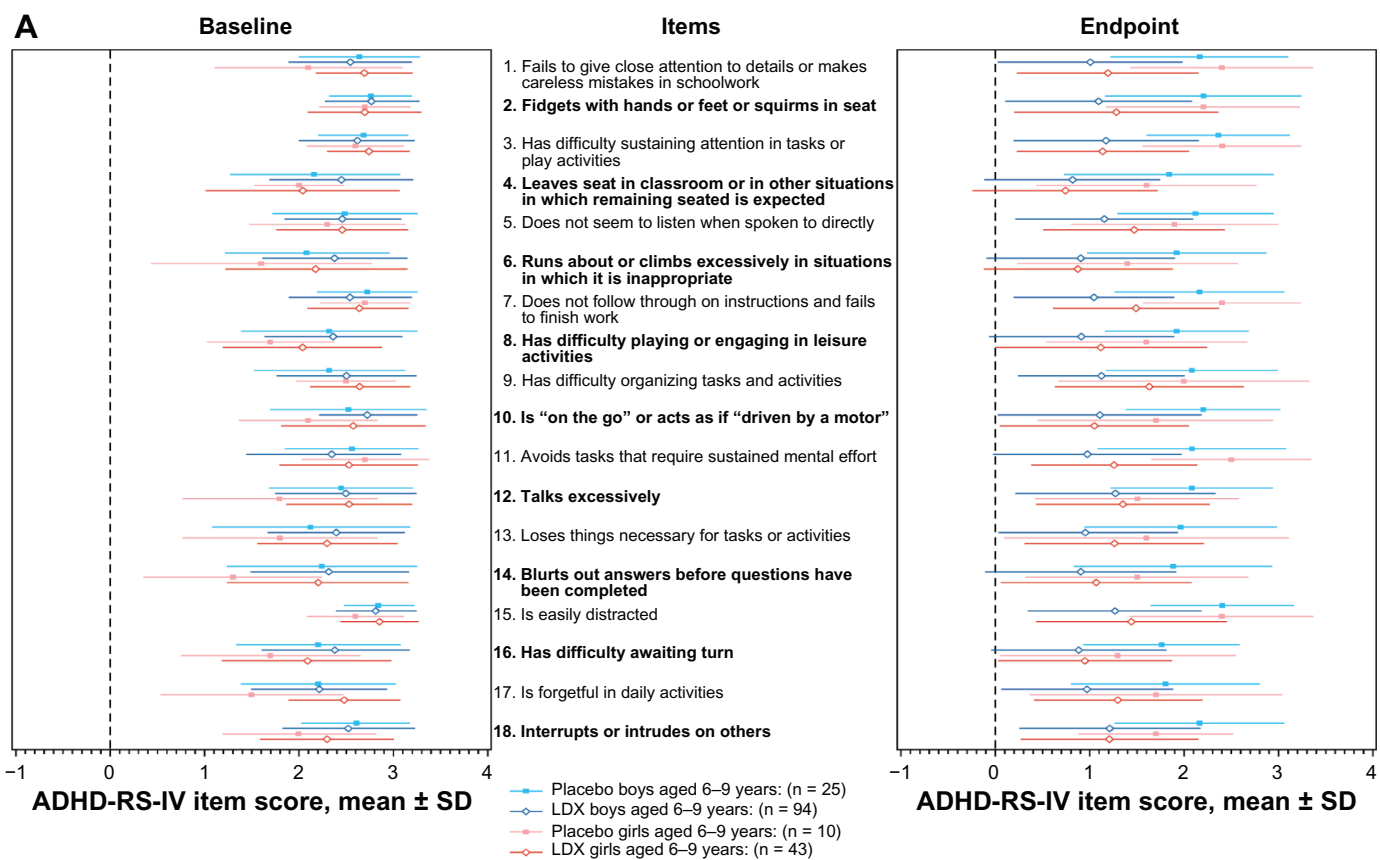

B

Items

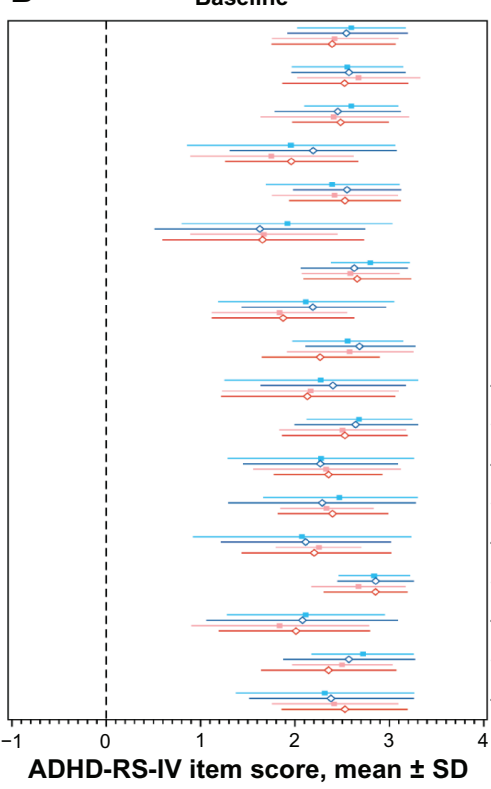

1. Fails to give close attention to details or makes 2. Fidgets with hands or feet or squirms in seat
a

3. Has difficulty sustaining attention in tasks or

4. Leaves seat in classroom or in other situations

Does not seem to listen when spoken to directly

6. Runs about or climbs excessively in situations in which it is inappropriate

7. Does not follow through on instructions and fails to finish work

8. Has difficulty playing or engaging in leisure

9. Has difficulty organizing tasks and activities

10. Is "on the go" or acts as if "driven by a motor"

11. Avoids tasks that require sustained mental effort

12. Talks excessively

13. Loses things necessary for tasks or activities 14. Blurts out answers before questions have 15. Is easily distracted

16. Has difficulty awaiting turn

17. Is forgetful in daily activities

18. Interrupts or intrudes on others

- Placebo boys aged 10-12 years: $(n=25)$

$\approx-$ LDX boys aged $10-12$ years: $(n=53)$
$\approx$ Placebo girls aged $10-12$ years: $(n=12)$

$\approx$ LDX girls aged $10-12$ years: $(n=23)$

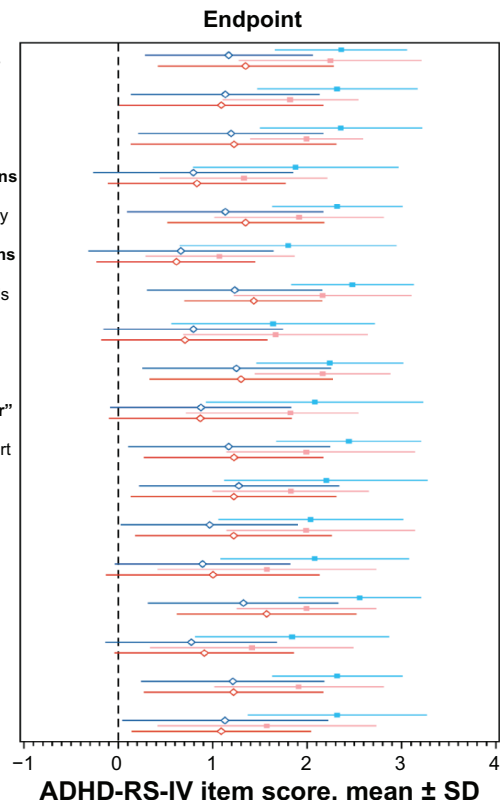

Figure 2 ADHD-RS-IV mean item scores by pediatric age and sex subgroups at baseline and endpoint. (A) Shows boys and girls aged 6 to 9 years; (B) shows boys and girls aged 10 to 12 years.

Notes: () 1998 Guildford Press. Adapted with permission from DuPaul GJ, Power TJ, Anastopoulos AD, Reid R. ADHD Rating Scale-IV: Checklists, Norms, and Clinical Interpretation. New York, NY: Guilford Press; $1998 .{ }^{38}$ Odd numbers = inattention items; even numbers = hyperactivity/impulsivity items. Adult prompts were used in the adult study. Bold text represents a hyperactivity/impulsivity item.

Abbreviations: ADHD-RS-IV, Attention-Deficit/Hyperactivity Disorder Rating Scale IV; LDX, lisdexamfetamine dimesylate; SD, standard deviation.

aged 40 to 55 years. Among the 278 females in the treated populations, 53 were aged 6 to 9 years, 35 were aged 10 to 12 years, 109 were aged 18 to 39 years, and 81 were aged 40 to 55 years. Almost all (except one participant) in both trials suffered from moderate to severe/extreme ADHD symptoms at baseline, as rated by the Clinical Global Impressions-Severity scale.
Overall ADHD-RS-IV mean item scores at baseline and after treatment

As described in the previous reports of the primary study analyses, all doses of LDX showed significant improvement vs placebo in mean changes from baseline to endpoint in the ADHD-RS-IV total mean item scores $(P<0.0001) .{ }^{30,31}$ For the current post hoc analyses, numerical differences 


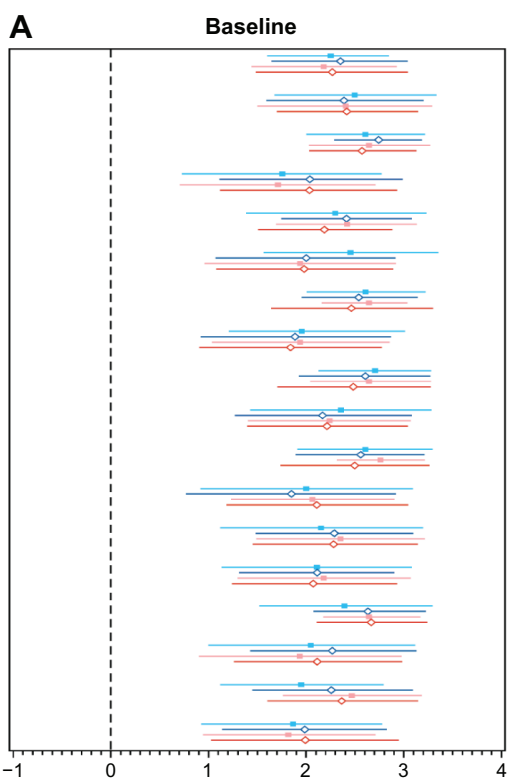

ADHD-RS-IV item score, mean \pm SD

B

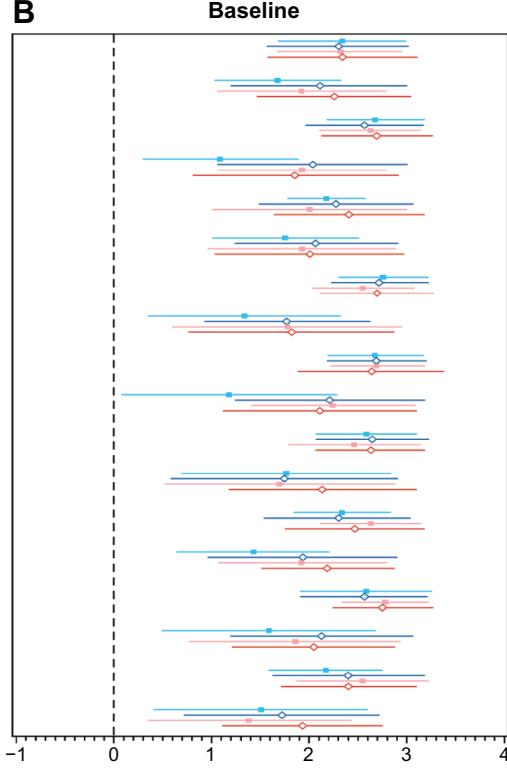

ADHD-RS-IV item score, mean \pm SD

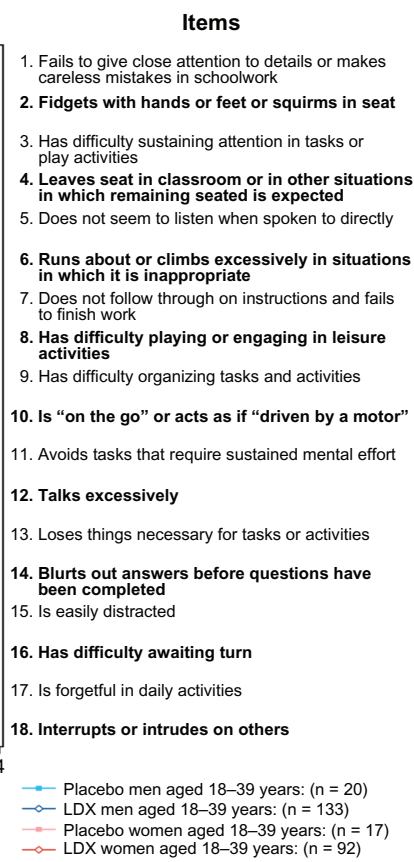

Items

1. Fails to give close attention to details or makes careless mistakes in schoolwork

3. Has difficulty sustaining attention in tasks or play activities

4. Leaves seat in classroom or in other situations 5. Does not seem to listen when spoken to directly

6. Runs about or climbs excessively in situations

7. Does not follow through on instructions and fails
to finish work

8. Has difficulty playing or engaging in leisure

9. Has difficulty organizing tasks and activities

10. Is "on the go" or acts as if "driven by a motor"

11. Avoids tasks that require sustained mental effort

12. Talks excessively

13. Loses things necessary for tasks or activities

14. Blurts out answers before questions have

15. Is easily distracted

16. Has difficulty awaiting turn

17. Is forgetful in daily activities

18. Interrupts or intrudes on others

- Placebo men aged 40-55 years: $(n=12)$

$\multimap-$ LDX men aged 40-55 years: $(n=59)$

- Placebo women aged 40-55 years: $(n=13)$

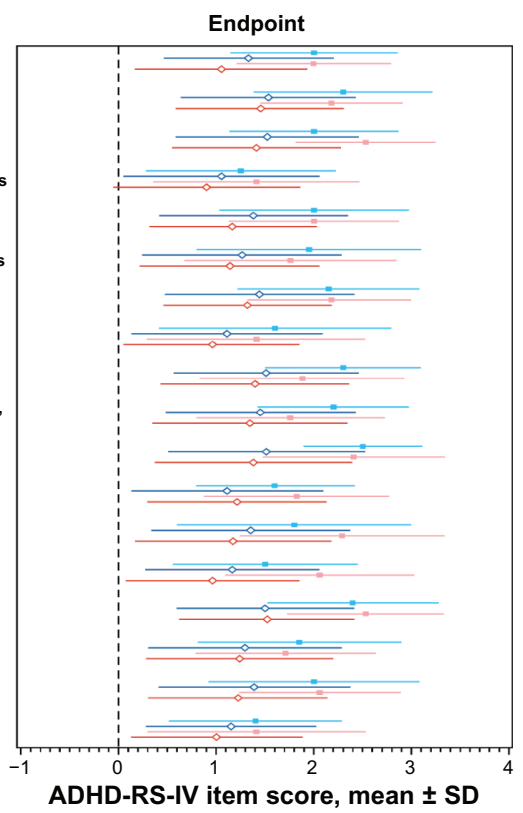

ADHD-RS-IV item score, mean \pm SD

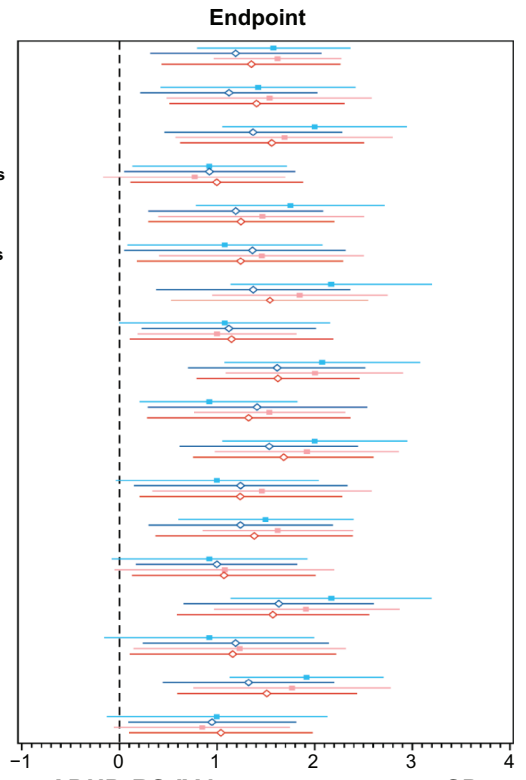

ADHD-RS-IV item score, mean \pm SD

Figure 3 ADHD-RS-IV mean item scores by adult age and sex subgroups at baseline and endpoint. (A) Shows men and women aged 18 to 39 years; (B) shows men and women aged 40 to 55 years.

Notes: ( 1998 Guildford Press. Adapted with permission from DuPaul GJ, Power TJ, Anastopoulos AD, Reid R. ADHD Rating Scale-IV: Checklists, Norms, and Clinical Interpretation. New York, NY: Guilford Press; $1998 .{ }^{38}$ Odd numbers = inattention items; even numbers = hyperactivity/impulsivity items. Adult prompts were used in the adult study. Bold text represents a hyperactivity/impulsivity item.

Abbreviations: ADHD-RS-IV, Attention-Deficit/Hyperactivity Disorder Rating Scale IV; LDX, lisdexamfetamine dimesylate; SD, standard deviation.

from baseline to endpoint in the actively treated population vs placebo were observed for all 18 of the ADHD-RS-IV mean item scores (Figure 1) in both children and adults. In the adult data, there was an observable pattern of numerically lower mean item baseline scores for the $\mathrm{H} / \mathrm{I}$ symptoms (evennumbered items) than for the IA symptoms (odd-numbered items) that was not seen in the child data. All items, however, showed numerical decreases at endpoint in both children and adults.

\section{Analysis of individual ADHD-RS-IV mean item scores by age and sex}

For the subgroups of boys and girls aged 6 to 9 years, the mean item baseline scores were numerically similar for 
Table I Participant disposition and baseline demographic data

\begin{tabular}{|c|c|c|}
\hline Disposition & $\begin{array}{l}\text { Pediatric } \\
\text { clinical trial }\end{array}$ & $\begin{array}{l}\text { Adult } \\
\text { clinical trial }\end{array}$ \\
\hline \multicolumn{3}{|l|}{ Treated population } \\
\hline$n$ & 285 & 414 \\
\hline Placebo, n (\%) & $72(25.3)$ & $62(15.0)$ \\
\hline Active, n (\%) & $213(74.7)$ & $352(85.0)$ \\
\hline \multicolumn{3}{|l|}{ Disposition, n (\%) } \\
\hline Completed & $230(80.7)$ & $349(84.3)$ \\
\hline Discontinued & $55(19.3)$ & $65(15.7)$ \\
\hline Treatment-emergent & $21(7.4)$ & $21(5.1)$ \\
\hline \multicolumn{3}{|l|}{ adverse events } \\
\hline Lack of efficacy & 14 (4.9) & $8(1.9)$ \\
\hline Protocol violation & $3(1.1)$ & $16(3.9)$ \\
\hline Lost to follow-up & $9(3.2)$ & $5(1.2)$ \\
\hline Withdrew consent & $3(1.1)$ & $9(2.2)$ \\
\hline Physician decision & $\mathrm{I}(0.4)$ & $2(0.5)$ \\
\hline Other & $4(1.4)$ & $4(1.0)$ \\
\hline \multicolumn{3}{|l|}{ Baseline demographic data } \\
\hline Age, mean (SD), y & $9.0(1.8)$ & $35.2(10.3)$ \\
\hline \multicolumn{3}{|l|}{ Sex, n (\%) } \\
\hline Female & $88(30.9)$ & $190(45.9)$ \\
\hline Male & $197(69.1)$ & $224(54.1)$ \\
\hline \multicolumn{3}{|l|}{ Age groups by sex, n (\%) } \\
\hline Female aged 6-9 years & $53(18.6)$ & \\
\hline Female aged $10-12$ years & $35(12.3)$ & \\
\hline Male aged 6-9 years & $119(41.8)$ & \\
\hline Male aged $10-12$ years & $78(27.4)$ & \\
\hline Female aged $18-39$ years & & $109(26.3)$ \\
\hline Female aged $40-55$ years & & $81(19.6)$ \\
\hline Male aged $18-39$ years & & $153(37.0)$ \\
\hline Male $40-55$ aged years & & $71(17.1)$ \\
\hline \multicolumn{3}{|l|}{ Race/ethnicity, n (\%) } \\
\hline African American & $69(24.2)$ & $14(3.4)$ \\
\hline Asian & $3(1.1)$ & $4(1.0)$ \\
\hline Caucasian & $152(53.3)$ & $344(83.1)$ \\
\hline Hispanic & $48(16.8)$ & $39(9.4)$ \\
\hline Native American & $2(0.7)$ & $3(0.7)$ \\
\hline Other & II (3.9) & $10(2.4)$ \\
\hline \multicolumn{3}{|l|}{ Global severity (CGI-S), n (\%) } \\
\hline Mildly ill & $\mathrm{I}(0.4)$ & 0 \\
\hline Moderately ill & $101(35.4)$ & $139(33.6)$ \\
\hline Markedly ill & $134(47.0)$ & $218(52.7)$ \\
\hline Severely ill & $45(15.8)$ & $56(13.5)$ \\
\hline Extremely ill & $4(\mathrm{I} .4)$ & $\mathrm{I}(0.2)$ \\
\hline
\end{tabular}

Abbreviations: CGI-S, Clinical Global Impressions-Severity scale; $n$, number; SD, standard deviation; $y$, year.

all items (Figure 2A, left panel). At baseline, for boys and girls aged 10 to 12 years, there were somewhat numerically higher IA (odd-numbered items) scores than H/I scores (even-numbered items) (Figure 2B, left panel). At endpoint, the mean item scores for all 18 items were numerically decreased in the active treatment groups among the boys and girls aged 6 to 9 years and 10 to 12 years (Figure 2A and B, right panels). Likely due to the small subgroup size, the mean item scores for the placebo group of girls aged 6 to 9 years were numerically variable, with greater breadth of SDs at both baseline and endpoint (Figure 2A, left and right panels).

For adults, as in the children aged 10 to 12 years, the IA mean item scores tended to be numerically higher than the H/I mean item scores; this was especially apparent among older (aged 40 to 55 years) men and women (Figure 3A and B, left panels). For the subgroup of men aged 40 to 55 years receiving placebo, the mean baseline item scores were somewhat more numerically variable, with a broader range of SDs, likely due to the relatively small subgroup size. At the endpoint, the mean item scores for all 18 items were numerically decreased in the active treatment groups among the men and women aged 18 to 39 years (Figure 3A, right panel). For the subgroups of men and women aged 40 to 55 years, the endpoint mean item scores were numerically decreased for participants in the active treatment groups and to some extent, for participants in the placebo groups (Figure 3B, right panel). In this older adult age group, there did not seem to be as much numerical variability in mean item scores at the endpoint for participants in the active treatment group vs the placebo group. Younger adults in the active treatment group had numerically decreased mean item scores compared with the placebo group; however, this group's overall population size was about two times larger than that of the older adult age group.

\section{Safety}

The details of the safety findings assessed in these trials have been previously described. ${ }^{30,31}$ In these two randomized, controlled trials, TEAEs were reported by 162 of 218 (74.3\%) participants in all the LDX dose groups and 34 of $72(47.2 \%)$ participants in the placebo group in the child study, and by 282 of 358 (78.8\%) participants taking LDX (at all doses) and 36 of the 62 (58.1\%) participants on placebo in the adult study. In the child study, the TEAEs with an incidence $\geq 5 \%$ in the combined LDX group were decreased appetite, insomnia, headache, upper abdominal pain, irritability, weight loss, vomiting, nausea, dizziness, and nasopharyngitis, and in the placebo group were headache, cough, nasal congestion, nasopharyngitis, and upper abdominal pain. ${ }^{30}$ In the randomized controlled trial in adults, the TEAEs with an incidence $\geq 5 \%$ in the combined LDX group were decreased appetite, dry mouth, headache, insomnia, nausea, diarrhea, irritability, anxiety, upper respiratory tract infection, anorexia, and initial insomnia. ${ }^{31}$ In both studies, LDX demonstrated a safety profile consistent with long-acting stimulant use. 


\section{Discussion}

In this set of post hoc analyses, we investigated the nature and severity of individual DSM-IV-TR ADHD symptoms in subgroups of children and adults, defined based on age and sex. In a previous post hoc analysis of data from a randomized, placebo-controlled, crossover study of LDX in children with ADHD, assessing behavior and performance using an analog classroom setting, minimal interaction effects were found for sex and age. ${ }^{39}$ Rather than analyze these data sets with a comparative statistical approach, a descriptive presentation of the pattern of symptom involvement and change in these subgroups was chosen. In addition to the previous findings above, the rationale for not pursuing comparative statistical analysis involved a consideration of several factors, including: prior commentary ${ }^{40,41}$ recommending against comparative statistical analysis of post hoc subgroup data sets; the small number of participants in many of the subgroups in the current study; the large number of analyses that would be required; and the lack of statistical power in the current analyses. The value of the current analysis was judged to be derived from examining the sex and age patterns for the ADHD symptom item analysis; to illustrate IA and H/I symptoms, showing the "pattern" of symptom involvement; and the relative improvement across the items.

The symptom item profiles were assessed before and after treatment with the long-acting stimulant LDX, to assess the similarities and differences in the profile of treatment-related changes in symptom severity. The baseline pretreatment ADHD-RS-IV mean item scores were numerically similar, regardless of age-by-sex subgroup, with the IA mean item scores tending to be numerically higher (more severe) than the H/I mean item scores, particularly among older adult participants. Overall, the endpoint ADHD-RS-IV mean item scores were numerically decreased with active treatment in both children and adults. The age-by-sex subgroup analysis showed that both IA and H/I symptoms decreased with active treatment among all subgroups examined, albeit with considerable variability. The greater variability, as shown by wider SDs, for some age-by-sex subgroups at either baseline or endpoint, especially for some subgroups receiving placebo, is likely to have been related to the smaller subgroup sizes since all the placebo groups had smaller sample sizes than the active treatment groups; smaller sample sizes decrease the precision of data and the ability to determine statistical relevance. With regard to baseline pretreatment symptom presentation, all age-by-sex subgroups generally exhibited broadly similar patterns and levels of symptom severity: for most age-by-sex subgroups, at baseline, IA mean item scores tended to be slightly numerically higher (ie, more severe) than were the H/I mean item scores, and this was more pronounced among older participants. It is unclear whether in the current post hoc analysis, the lack of definitive sex-related differences in symptom presentation in children was due to the exclusion from the present trial of individuals with the predominantly IA subtype, as this may be seen more often in females. Consequently, these findings may differ from previous research because those earlier efforts reflect a more symptomatically homogeneous sample that includes the predominantly IA subtype. Nevertheless, the current findings are in agreement with those of Sobanski et al, ${ }^{23}$ who found the IA and H/I subtypes in roughly equal proportions of clinic-referred adult men and women with ADHD, which suggests that the present analysis may accurately reflect symptom presentation in men and women.

However, the current findings support prior research indicating age-related differences in symptom presentation at baseline, with older participants showing more pronounced IA symptoms relative to H/I symptoms. Our findings are in line with previous findings suggesting that $\mathrm{H} / \mathrm{I}$ symptoms tend to decrease with increasing age while IA symptoms are more constant with increasing age. ${ }^{6-8,38}$ However, it is worth noting that while this and previous studies suggest differences in symptom presentation according to patient age, it is not clear whether these are related to real differences in the presence and severity of symptoms or are related to different forms of symptom expression between younger and older individuals. ${ }^{9}{ }^{14}$ Some researchers have argued that reported decreases in H/I may reflect changing manifestations not captured by the DSM-IV-TR criteria, rather than the true resolution of H/I symptoms. ${ }^{9,13}$ With maturation, hyperactivity may begin to manifest as inner restlessness, feeling uncomfortable sitting for lengthy periods, or being unwilling to wait in line. ${ }^{13}$ Impulsivity may manifest as increased frustration or explosive emotional episodes. ${ }^{14}$ In line with these arguments, in a 5-year longitudinal study (mean baseline age of $\sim 13$ years), there was poor diagnostic stability for the major DSM-IV ADHD subtypes. ${ }^{8}$ The highest rates of stability were observed for the combined subtype (24\%), while the lowest rate (11\%) was observed for the predominantly $\mathrm{H} / \mathrm{I}$ subtype. It seems possible that such instability may, at least in part, reflect an issue with the diagnostic criteria, rather than an actual change in ADHD subtype. Questions surrounding the changing profile of symptom manifestation during development are apparent from the lack of developmentally appropriate descriptions of the defining symptoms for 
individuals who are in transition from early childhood to middle childhood, adolescence, and adulthood, ${ }^{9}$ in the DSMIV-TR. The revised criteria for the DSM-5 (completed in 2013) may help to resolve these challenges in the diagnosis of ADHD in older patients. A recently published study ${ }^{12}$ of large community-based (National Comorbidity Survey Replication) and managed health care populations has corroborated the previously mentioned finding of Millstein et $\mathrm{al}^{10}$ and also documented increased IA vs H/I symptom loading in adults with ADHD.

\section{Limitations}

Several important limitations of the present post hoc analyses warrant consideration. The studies were not prospectively powered to detect differences among the subgroups examined; some sample sizes, especially in the placebo subgroups, were small, resulting in substantial variability in some of the baseline ADHD-RS-IV item scores and in the difference scores for LDX vs placebo. This was generally manifested by larger SDs for item scores and may have accounted for some of the variability between participants in the LDX or placebo groups at baseline. No tests of internal consistency, reliability, or factor analyses were performed, as this post hoc analysis was not intended to validate the ADHD-RS scale. Caution should be considered in generalizing the results to the overall ADHD population in light of a potential selection bias due to exclusion of the IA subtype in the pediatric trial. As well, the baseline severity requirements of ADHD-RS-IV total score $\geq 28$ may have masked differences that occur in the general population of ADHD patients; females, as well as older children and adults, have been noted to express more IA symptomatology vs that of H/I. Importantly, since the pediatric trials explicitly excluded participants diagnosed with the predominantly IA subtype, this potentially limits the ability to detect differential effects of participant variables and treatment on the IA symptom clusters. These were exploratory, post hoc analyses, so groups were not matched and data analysis was limited to descriptive statistical comparisons. Formal hypothesis testing was not performed. Certain aspects of the previous child and adult studies limit the ability to generalize the findings to clinical situations, including use of forced-dose titration designs, relatively short treatment duration (4 weeks), exclusion of adolescent participants (aged 13 to 17 years), and enrollment of clinic-referred participants with moderate to severe ADHD symptoms.

In conclusion, these post hoc subgroup analyses suggest that the presentation of individual DSM-IV-TR ADHD symptoms, for those with combined or H/I subtype ADHD, was generally similar regardless of participants' sex, but with older children and adults tending to exhibit more severe IA than H/I symptoms. Moreover, the endpoint ADHD-RS-IV items mean scores were generally numerically lower after active treatment for most IA and H/I symptom items in most of the age-by-sex subgroups, suggesting that ADHD symptoms are broadly responsive to effective treatment. The current findings add to the growing literature surrounding age- and sex-related differences in ADHD symptom presentation and treatment response, and this continues to be an important area in need of further research.

\section{Acknowledgments}

The clinical research was funded by the sponsor, Shire Development LLC. Under the direction of the authors, Karen Dougherty, PhD, a former employee, and Michael Pucci, $\mathrm{PhD}$, an employee of SCI Scientific Communications \& Information (SCI), provided writing assistance for this publication. Editorial assistance in formatting, proofreading, copy editing, and fact checking was also provided by SCI. Thomas Babcock, DO, and Brian Scheckner, PharmD, from Shire Development LLC also reviewed and edited the manuscript for scientific accuracy. Shire Development LLC provided funding to SCI for support in writing and editing this manuscript. Although the sponsor was involved in the design, collection, analysis, interpretation, and fact checking of information, the content of this manuscript, the ultimate interpretation, and the decision to submit it for publication in Neuropsychiatric Disease and Treatment were made by the authors independently.

\section{Disclosure}

Richard H Weisler, MD, has been a consultant to, on the Speaker's Bureau of, and/or received research support from the following: Abbott - Speaker's Bureau, Consultant, received research support; Alcobra - Consultant; Agency for Toxic Substances and Disease Registry - Consultant; Astra Zeneca - Speaker's Bureau, Consultant, received research support; Biovail - Speaker's Bureau, Consultant, received research support; Bristol-Myers Squibb - Speaker's Bureau, Consultant, received research support, Stockholder has held or holds stock; Burroughs Wellcome - Speaker's Bureau, received research support; Cenerx - received research support; Centers for Disease Control and Prevention - Consultant; Cephalon - Speaker's Bureau, Consultant, received research support; Ciba Geigy - Speaker's Bureau, received research support; CoMentis - received research support; Corcept - Consultant; Cortex - Stockholder has 
held or holds stock; Dainippon Sumitomo Pharma America - received research support; Eisai - received research support; Elan - received research support; Eli Lilly - Speaker's Bureau, Consultant, received research support; Forest Speaker's Bureau, Consultant, received research support; GlaxoSmithKline - Speaker's Bureau, Consultant, received research support; Janssen - Speaker's Bureau, received research support; Johnson \& Johnson - Speaker's Bureau, Consultant, received research support; Lundbeck - received research support; McNeil Pharmaceuticals - received research support; Medicinova - received research support; Medscape Advisory Board - Consultant; Merck - received research support, Speaker's Bureau, Stockholder has held or holds stock; National Institute of Mental Health - Consultant, received research support; Neurochem - received research support; New River Pharmaceuticals - received research support; Novartis - Speaker's Bureau, received research support; Organon - Speaker's Bureau, Consultant, received research support; Otsuka America Pharma - Consultant; Pfizer Speaker's Bureau, Consultant, received research support, Stockholder has held or holds stock; Pharmacia-Consultant, received research support; Repligen - received research support; Saegis - received research support; Sandoz - received research support; Sanofi - Speaker's Bureau, Consultant, received research support; Sanofi-Synthelabo - Speaker's Bureau, Consultant, received research support; Schwabe/ Ingenix - received research support; Sepracor - received research support; Shire - Speaker's Bureau, Consultant, received research support; Solvay - Speaker's Bureau, Consultant; Sunovion - Speaker's Bureau, Consultant, received research support; Synaptic - received research support; Takeda - received research support; TAP - received research support; Theravance - received research support; Transcept Pharma - Consultant, received research support; TransTech - Consultant; UCB Pharma - received research support; Validus - Speaker's Bureau, Consultant; Vela - received research support; and Wyeth - Speaker's Bureau, Consultant, received research support. Lenard A Adler, MD, has been a consultant to AstraZeneca, Eli Lilly, Epi-Q, i3 Research, INC Research, Mindsite, Organon/ Schering-Plough/Merck, Ortho-McNeil/Janssen/Johnson \& Johnson, Otsuka, Shire, United Biosource, Major League Baseball, Major League Baseball Players Association, the National Football League, Alcobra Pharmaceuticals and Theravance; he has received research support from Bristol-Myers Squibb, Chelsea Therapeutics, Eli Lilly, Organon/Schering-Plough/Merck, Ortho-McNeil/Janssen/
Johnson \& Johnson and the National Institute of Drug Abuse (NIDA); he has been on the advisory boards of Eli Lilly, i3 Research, INC Research, Mindsite, Organon/ Schering-Plough/Merck, Ortho-McNeil/Janssen/Johnson \& Johnson, Theravance and Alcobra Pharmaceuticals. He has previously been (and has not been for the last three years) on the Speaker's Board for Ortho-McNeil/Janssen/Johnson \& Johnson, Shire and Eli Lilly. He has received an options grant from Alcobra Pharmaceuticals and has received royalty payments (as inventor) from New York University for license of adult ADHD scales and training materials. Scott H Kollins, $\mathrm{PhD}$, has received research support and/or consulting fees from the following: Addrenex/Shionogi, Akili Interactive, Arbor, Atentiv, Neos, NIH, Otsuka, Pfizer, Purdue, Rhodes, Shire, and Sunovion. David W Goodman, MD, has been a speaker and consultant for, has received honoraria from, and has received research support from various agencies, including the American Professional Society of ADHD and Related Disorders, and medical/pharmaceutical companies, including the sponsor, Shire. Mohamed Hamdani, MS, is an employee of Shire and holds stock and/or stock options in Shire Inc. Bryan Dirks, MD, is an employee of Shire and holds stocks and/or stock options in Johnson \& Johnson and Shire. Ann $\mathrm{C}$ Childress, MD, has been a speaker and consultant for and received research/grant support from various pharmaceutical companies, including Shire.

\section{References}

1. Froehlich TE, Lanphear BP, Epstein JN, Barbaresi WJ, Katusic SK, Kahn RS. Prevalence, recognition, and treatment of attention-deficit/ hyperactivity disorder in a national sample of US children. Arch Pediatr Adolesc Med. 2007;161(9):857-864.

2. Centers for Disease Control and Prevention (CDC). Increasing prevalence of parent-reported attention-deficit/hyperactivity disorder among children - United States, 2003 and 2007. MMWR Morb Mortal Wkly Rep. 2010;59(44):1439-1443.

3. Lara C, Fayyad J, de Graaf R, et al. Childhood predictors of adult attention-deficit/hyperactivity disorder: results from the World Health Organization World Mental Health Survey Initiative. Biol Psychiatry. 2009;65(1):46-54.

4. Schubiner H, Katragadda S. Overview of epidemiology, clinical features, genetics, neurobiology, and prognosis of adolescent attentiondeficit/hyperactivity disorder. Adolesc Med State Art Rev. 2008;19(2): 209-215, vii.

5. Kessler RC, Adler L, Barkley R, et al. The prevalence and correlates of adult ADHD in the United States: results from the National Comorbidity Survey Replication. Am J Psychiatry. 2006;163(4):716-723.

6. Biederman J, Mick E, Faraone SV. Age-dependent decline of symptoms of attention deficit hyperactivity disorder: impact of remission definition and symptom type. Am J Psychiatry. 2000;157(5):816-818.

7. Hart EL, Lahey BB, Loeber R, Applegate B, Frick PJ. Developmental change in attention-deficit hyperactivity disorder in boys: a four-year longitudinal study. J Abnorm Child Psychol. 1995;23(6): 729-749. 
8. Todd RD, Huang H, Todorov AA, et al. Predictors of stability of attentiondeficit/hyperactivity disorder subtypes from childhood to young adulthood. J Am Acad Child Adolesc Psychiatry. 2008;47(1): 76-85.

9. Adler LA, Spencer TJ, Biederman J, et al. The internal consistency and validity of the attention-deficit/hyperactivity disorder rating scale (ADHD-RS) with adult ADHD prompts as assessed during a clinical treatment trial. J ADHD Relate Disord. 2009;1(1):14-24.

10. Millstein RB, Wilens TE, Biederman J, Spencer TJ. Presenting ADHD symptoms and subtypes in clinically referred adults with ADHD. JAtten Disord. 1997;2(3):159-166.

11. American Psychiatric Association. Diagnostic and Statistical Manual of Mental Disorders DSM-IV-TR, Fourth Edition. Text Revision. Arlington, VA: American Psychiatric Association; 2000.

12. Kessler RC, Green JG, Adler LA, et al. Structure and diagnosis of adult attention-deficit/hyperactivity disorder: analysis of expanded symptom criteria from the Adult ADHD Clinical Diagnostic Scale. Arch Gen Psychiatry. 2010;67(11):1168-1178.

13. Weiss MD, Weiss JR. A guide to the treatment of adults with ADHD. $J$ Clin Psychiatry. 2004;65 Suppl 3:27-37.

14. Wilens TE, Dodson W. A clinical perspective of attention-deficit/ hyperactivity disorder into adulthood. J Clin Psychiatry. 2004;65(10): 1301-1313.

15. Hervey AS, Epstein JN, Curry JF. Neuropsychology of adults with attention-deficit/hyperactivity disorder: a meta-analytic review. Neuropsychology. 2004;18(3):485-503.

16. Epstein JN, Johnson DE, Varia IM, Conners CK. Neuropsychological assessment of response inhibition in adults with ADHD. J Clin Exp Neuropsychol. 2001;23(3):362-371.

17. Malloy-Diniz L, Fuentes D, Leite WB, Correa H, Bechara A. Impulsive behavior in adults with attention deficit/hyperactivity disorder: characterization of attentional, motor and cognitive impulsiveness. J Int Neuropsychol Soc. 2007;13(4):693-698.

18. Gibbins C, Weiss M. Clinical recommendations in current practice guidelines for diagnosis and treatment of ADHD in adults. Curr Psychiatry Rep. 2007;9(5):420-426.

19. American Academy of Pediatrics Committee on Quality Improvement and Subcommittee on Attention-Deficit/Hyperactivity Disorder. Clinical practice guideline: diagnosis and evaluation of the child with attentiondeficit/hyperactivity disorder. Pediatrics. 2000;105(5):1158-1170.

20. Wolraich ML, Hannah JN, Pinnock TY, Baumgaertel A, Brown J. Comparison of diagnostic criteria for attention-deficit hyperactivity disorder in a county-wide sample. J Am Acad Child Adolesc Psychiatry. 1996;35(3):319-324.

21. Barbaresi WJ, Katusic SK, Colligan RC, Weaver AL, Leibson CL, Jacobsen SJ. Long-term stimulant medication treatment of attentiondeficit/hyperactivity disorder: results from a population-based study. J Dev Behav Pediatr. 2006;27(1):1-10.

22. Robison RJ, Reimherr FW, Marchant BK, Faraone SV, Adler LA, West SA. Gender differences in 2 clinical trials of adults with attentiondeficit/hyperactivity disorder: a retrospective data analysis. J Clin Psychiatry. 2008;69(2):213-221.

23. Sobanski E, Brüggemann D, Alm B, et al. Subtype differences in adults with attention-deficit/hyperactivity disorder (ADHD) with regard to ADHD-symptoms, psychiatric comorbidity and psychosocial adjustment. Eur Psychiatry. 2008;23(2):142-149.

24. Zucker M, Morris MK, Ingram SM, Morris RD, Bakeman R. Concordance of self- and informant ratings of adults' current and childhood attention-deficit/hyperactivity disorder symptoms. Psychol Assess. 2002;14(4):379-389.

25. Pliszka S; AACAP Work Group on Quality Issues. Practice parameter for the assessment and treatment of children and adolescents with attention-deficit/hyperactivity disorder. J Am Acad Child Adolesc Psychiatry. 2007;46(7):894-921.
26. Greenhill LL, Pliszka S, Dulcan MK, et al; American Academy of Child and Adolescent Psychiatry. Practice parameter for the use of stimulant medications in the treatment of children, adolescents, and adults. J Am Acad Child Adolesc Psychiatry. 2002;41(Suppl 2):26S-49S.

27. Faraone SV, Buitelaar J. Comparing the efficacy of stimulants for ADHD in children and adolescents using meta-analysis. Eur Child Adolesc Psychiatry. 2010;19(4):353-364.

28. Faraone SV, Glatt SJ. A comparison of the efficacy of medications for adult attention-deficit/hyperactivity disorder using meta-analysis of effect sizes. J Clin Psychiatry. 2010;71(6):754-763.

29. Vyvanse ${ }^{\circledR}$ (lisdexamfetamine dimesylate) [package insert]. Wayne, PA: Shire US Inc; 2012.

30. Biederman J, Krishnan S, Zhang Y, McGough JJ, Findling RL. Efficacy and tolerability of lisdexamfetamine dimesylate (NRP-104) in children with attention-deficit/hyperactivity disorder: a phase III, multicenter, randomized, double-blind, forced-dose, parallel-group study. Clin Ther. 2007;29(3):450-463.

31. Adler LA, Goodman DW, Kollins SH, et al; 303 Study Group. Double-blind, placebo-controlled study of the efficacy and safety of lisdexamfetamine dimesylate in adults with attention-deficit/hyperactivity disorder. J Clin Psychiatry. 2008;69(9):1364-1373.

32. Findling RL, Ginsberg LD, Jain R, Gao J. Effectiveness, safety, and tolerability of lisdexamfetamine dimesylate in children with attentiondeficit/hyperactivity disorder: an open-label, dose-optimization study. J Child Adolesc Psychopharmacol. 2009;19(6):649-662.

33. Findling RL, Childress AC, Krishnan S, McGough JJ. Long-term effectiveness and safety of lisdexamfetamine dimesylate in schoolaged children with attention-deficit/hyperactivity disorder. CNS Spectr. 2008;13(7):614-620.

34. Weisler R, Young J, Mattingly G, Gao J, Squires L, Adler L; 304 Study Group. Long-term safety and effectiveness of lisdexamfetamine dimesylate in adults with attention-deficit/hyperactivity disorder. CNS Spectr. 2009;14(10):573-585.

35. Biederman J, Boellner SW, Childress A, Lopez FA, Krishnan S, Zhang Y. Lisdexamfetamine dimesylate and mixed amphetamine salts extended-release in children with ADHD: a double-blind, placebo-controlled, crossover analog classroom study. Biol Psychiatry. 2007;62(9):970-976.

36. Wigal SB, Kollins SH, Childress AC, Squires L; 311 Study Group. A 13-hour laboratory school study of lisdexamfetamine dimesylate in school-aged children with attention-deficit/hyperactivity disorder. Child Adolesc Psychiatry Ment Health. 2009;3(1):17.

37. Wigal T, Brams M, Gasior M, Gao J, Squires L, Giblin J; 316 Study Group. Randomized, double-blind, placebo-controlled, crossover study of the efficacy and safety of lisdexamfetamine dimesylate in adults with attention-deficit/hyperactivity disorder: novel findings using a simulated adult workplace environment design. Behav Brain Funct. 2010;6:34.

38. DuPaul GJ, Power TJ, Anastopoulos AD, Reid R. ADHD Rating Scale-IV: Checklists, Norms, and Clinical Interpretation. New York, NY: Guilford Press; 1998.

39. Wigal SB, Kollins SH, Childress AC, Adeyi B. Efficacy and tolerability of lisdexamfetamine dimesylate in children with attention-deficit/ hyperactivity disorder: sex and age effects and effect size across the day. Child Adolesc Psychiatry Ment Health. 2010;4:32.

40. Lagakos SW. The challenge of subgroup analyses - reporting without distorting. N Engl J Med. 2006;354(16):1667-1669.

41. Wang R, Lagakos SW, Ware JH, Hunter DJ, Drazen JM. Statistics in medicine - reporting of subgroup analyses in clinical trials. $N$ Engl $J$ Med. 2007;357(21):2189-2194. 


\section{Publish your work in this journal}

Neuropsychiatric Disease and Treatment is an international, peerreviewed journal of clinical therapeutics and pharmacology focusing on concise rapid reporting of clinical or pre-clinical studies on a range of neuropsychiatric and neurological disorders. This journal is indexed on PubMed Central, the 'PsycINFO' database and CAS.

The manuscript management system is completely online and includes a very quick and fair peer-review system, which is all easy to use. Visit http://www.dovepress.com/testimonials.php to read real quotes from published authors.

\footnotetext{
Submit your manuscript here: http://www.dovepress.com/neuropsychiatric-disease-and-treatment-journal
} 